\title{
Commissioning of HVAC systems in a campus building with regard to the indoor environment and energy performance
}

\author{
Chen Zhang, Adam Stoltenberg Iversen, Anda Senberga, Andras Cedl, Liena Krastina, Vilija \\ Matuleviciute, Evangelia Loukou, Mingzhe Liu, Anna Joanna Marszal \\ Department of Civil Engineering, Aalborg University, Aalborg 9200, Denmark
}

\begin{abstract}
Today's HVAC systems in the building sector become more and more complex in order to fulfill the increasing standard of the indoor environment, which typically have many components, sub-systems, and controls. Commissioning is a quality-oriented process to verify and document that the performance of buildings and HVAC systems fulfill the defined objectives and criteria. This study demonstrates the commissioning process in a campus building in Denmark. By analyzing the monitored date from BMS and on-site measurements, some fault operations and controls in the HVAC systems are identified, for example, improper setpoint for heating and ventilation, fault location of temperature and $\mathrm{CO} 2$ sensors, too high return temperature for district heating, etc. A building simulation model is developed and validated in order to test the optimization strategies and evaluate the energy conservation potential. An energy saving ranges from $20 \%-42 \%$ is realized after the implementation of the optimization strategies.
\end{abstract}

\section{Introduction}

Nowadays, the HVAC systems in the building sector become more and more complex in order to fulfill the increasing standard of the indoor environment. Among building services, the growth of energy consumption by HVAC systems is especially significant, which accounts up to $48 \%$ of total building consumption in EU and more than $57 \%$ in the USA (Pérez-Lombard et al. 2008). The performance of the HVAC system may deviate from the design requirements due to improper installation, equipment corrosion, sensor drifts, lack of maintenance, or improper control and regulation systems. The commissioning process is a quality-oriented process to verify and document that the performance of buildings and systems fulfill the defined objectives and criteria (Dorgan et al. 2007). Based on the findings by Annex 40 and Annex 47, most faults identified through commissioning occurred in HVAC systems, for example, air-handling systems, heating and chilled water plants (Friedman et al. 2010; Milesi et al. 2018).

Commissioning could be conducted by tend data analysis and functional test to detect and diagnose the faults in the system and further propose a complete solution and correction action. Monitoring-based commissioning $(\mathrm{MBCx})$ is a highly effective and low cost approach to keep building performance in check(Harmer et al. 2015;
Brown et al. 2006). By tracking the energy or indoor environment data from building management system, it allows building owners and operators to ensure that building is running based on design requirements. $\mathrm{MBCX}$ is commonly coupled with calibrated building simulation models to extend their diagnostic capabilities through the adoption of dynamic and relevant baselines(Harmer et al. 2015). The goal of commissioning is to reduce the cost of building operation and improve the performance of building systems but does not involve large capital investments on equipment (Wang et al. 2013). Many building owners have realized that commissioning is a useful approach for improving building performance during its life cycle.

This study demonstrates the commissioning process in a campus building in Denmark. The aim of commissioning is to evaluate the building performance in term of indoor environment and energy use, and seek for possible improvements and alternations to the control and operation of the HVAC systems that could benefit the building owners as well as the occupants. The main focus of system analysis is ventilation and heating. The commissioning activities include system observation, monitoring data analysis, and on-site measurements. The collected information and data from the above activities are used to develop a building simulation model and a dynamic simulation software BSim is applied in this study. The validated model can be used as a reference model for on-going commissioning to test the optimization strategies and evaluate the energy conservation potential.

\section{Building and systems description}

The building located in Aalborg, Denmark was constructed in 2015 and started to operate in April 2016. The function is office facilities with associated meeting rooms, group rooms, lunchroom and auditorium. The building has two floors and the total floor area is $3198 \mathrm{~m}^{2}$. The building is designed so that most of the working rooms, including offices, and meeting rooms, are located towards the external side of the building and the others have windows toward the three centrally located atriums in the building, in order to benefit from the daylight, as it can also be seen in Figure 1. The physic characteristics of building envelopes are listed in Table 1. It is clear to see that the envelops are designed to fulfill the Danish building regulation BR15 (The Danish Ministry of Economic and Business Affairs 2015). 
Table 1: Physical characteristics of building envelop.

\begin{tabular}{|c|c|c|c|}
\hline Building envelop & & BR15 & $\begin{array}{l}\text { Case } \\
\text { building }\end{array}$ \\
\hline Terrain slab & \multirow{4}{*}{$\begin{array}{l}\text { U-value } \\
{\left[\mathrm{W} / \mathrm{m}^{2} \cdot \mathrm{K}\right]}\end{array}$} & 0.15 & 0.07 \\
\hline External wall & & 0.15 & 0.12 \\
\hline Roof & & 0.1 & 0.08 \\
\hline Windows & & 1.4 & 0.8 \\
\hline Infiltration@ @50 Pa & {$\left[1 / \mathrm{s} . \mathrm{m}^{2}\right]$} & 1 & 0.6 \\
\hline
\end{tabular}

A building management system (BMS) is implemented in this building to control and monitors the building HVAC system and lighting, window opening. It manages the data inputs from sensors, performs calculations according to predefined strategies, and practices control over components and parts of the system, e.g., fans, valves, pumps. Figure 1 shows the four different room types regarding control and sensor types. The available information from the BMS is different for these rooms in relation to heating, ventilation, and lighting. The control strategies in different rooms are explained in Table 2.

The building has three ventilation systems installed. VE01 and VE02 are centralized air handling units (AHU) located in the technical room. As shown in Figure 2, the supply section consists of on-off damper, filter, rotary heat exchanger, heating coil and supply air fan, in the end, there is a heating coil, while, the exhaust section consists of: exhaust fan, rotary heat exchanger, filter and on-off damper. VE01 is used to ventilate offices and meeting rooms, while VE02 is only used to ventilate auditorium. VU01-4 includes four exhaust systems, which extract polluted air from toilets. The supply air temperature of AHUs varies based on the outdoor temperature. There is no cooling system in this building, therefore, a night cooling function will be activated if the following conditions are fulfilled: Outdoor temperature is $3{ }^{\circ} \mathrm{C}$ lower than room temperature; room temperature is higher than $23{ }^{\circ} \mathrm{C}$; outdoor temperature is higher than $10^{\circ} \mathrm{C}$; less than 5 hours to switch to daytime operation mode. Detail description of ventilation systems refer to Table 3

The heating system in the building is supplied from the district heating terminal. It is divided into two mixing loops, RA01 for the South/ West facing part of the building, and RA02 for the North/ East orientations, see Figure 3 . The supply temperature is controlled by a time schedule that controls the set-points. The time schedule has two modes, day operation and night setback. The day operation is active between 04:00 and 22:00 after which the night setback is active. The day operation starts this soon because the system has to heat the rooms before the occupants show up. The temperature of the return water is controlled and kept below $50{ }^{\circ} \mathrm{C}$, the highest value allowed by the BMS is $60^{\circ} \mathrm{C}$. If those limits are violated the alarm goes off and the pump is shut down.

The heating terminals used in the offices and meeting rooms are radiators. While, the primary heating demand in the auditorium is fulfilled by the ventilation system, supplemented by radiators located at the bottom and top levels of the space. The heating demand (flow rate) of radiators are controlled by thermostatic valves.

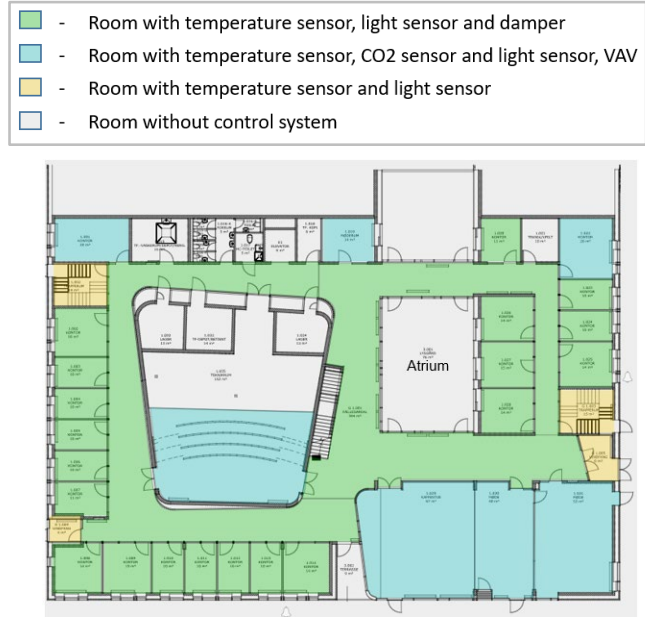

(a)

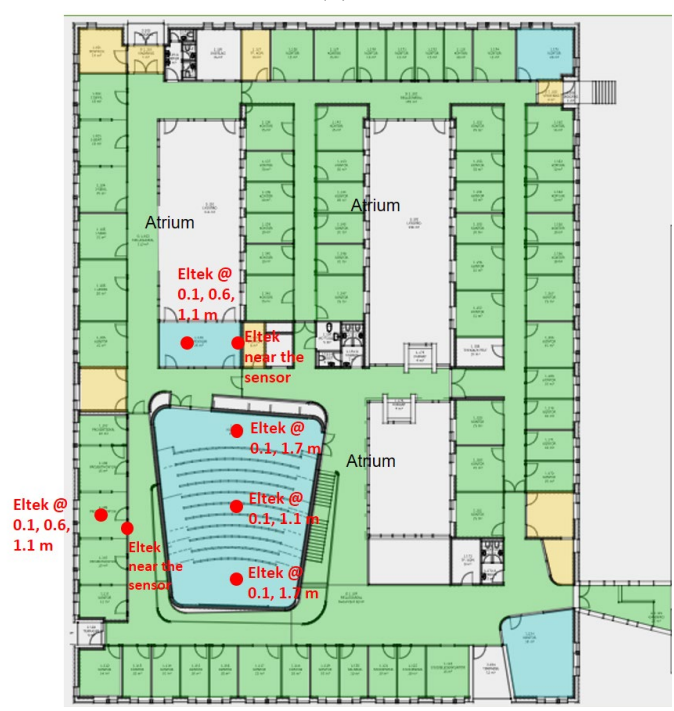

(b)

Figure 1: Building floor plan, control strategies and measured positions. (a) Ground floor; (b) First floor

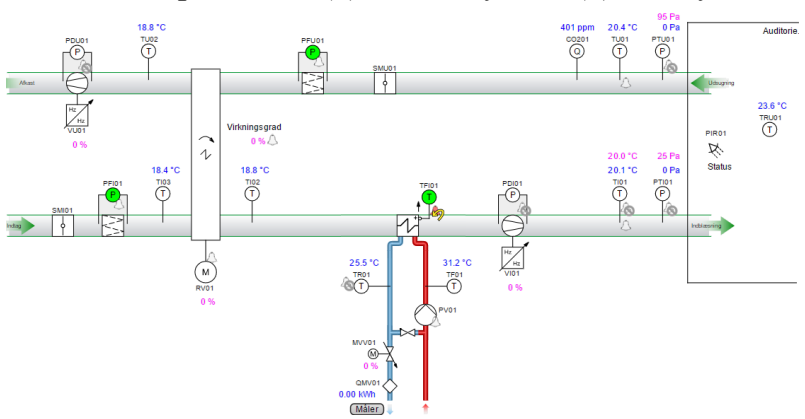

Figure 2: BMS interface of VE02 AHU system and the control system.

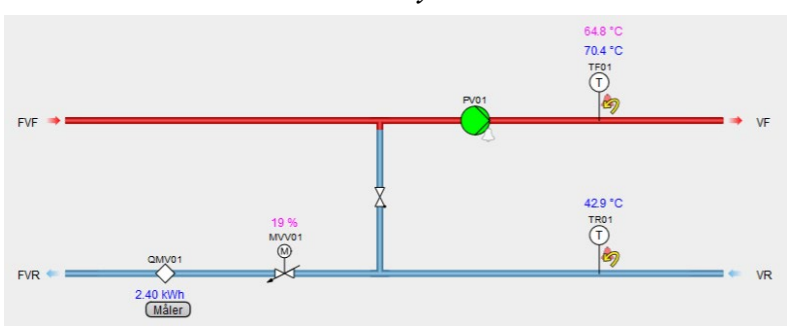

Figure 3: BMS interface of RA01 heating loop and the control system. 


\section{Methodology}

Monitor-data from BMS system and energy monitoring are used to conduct trend analysis, which is a critical approach in the process of building commissioning to detect fault operation in the HVAC systems. Beside monitor-data analysis, on-site measurement was performed in a period of one month (2.3.2018-2.4.2018). The purpose of the on-site measurement is to investigate the indoor environment in different types of room and to validate BMS monitored data. Three rooms are selected, one office, one meeting room and the auditorium, and Eltek sensors are placed at different locations to measure $\mathrm{CO} 2$, temperature and relative humidity, as shown in Figure 1. At the same time, a blower door test was conducted to exam the infiltration rate and the results are shown in Table 1.

The collected information and data from the above activities are used to develop a building simulation model and a dynamic simulation software BSim is applied in this study. The validated model can be used as a reference model for on-going commissioning to test the optimization strategies and evaluate the energy conservation potential.

\section{Results and Discussion}

\section{Ventilation systems}

The damper position in relation to the indoor $\mathrm{CO} 2$ level and temperature level in three different rooms is analyzed here, as illustrated in Figure 5. It is clear to see that damper only operates in on/off model in the office. The damper is controlled by occupancy monitored by PIR sensors, this is explained why the damper has a short turn off period during the lunch hour. There is no $\mathrm{CO} 2$ sensor in the office. Eltek sensors measured the $\mathrm{CO} 2$ level at two positions, which indicates a good mixing has been reached in the room. However, it also reveals that the constant flow rate is not able to handle the excess $\mathrm{CO} 2$ level, where the $\mathrm{CO} 2$ reaches approximately $1400 \mathrm{ppm}$ in $16^{\text {th }}$ March.

The damper in the meeting room can operate in three models: $0 \%, 40 \%$ and $100 \%$. The damper will open to $40 \%$ when the PIR sensor detected the occupancy. The damper opening will increase to $100 \%$ when the CO2 level exceeds the setpoint of $1000 \mathrm{ppm}$. However, even the damper operated at $100 \%$ opening, the $\mathrm{C} 02$ level still exceeded $1000 \mathrm{ppm}$ in $15^{\text {th }}$ and $16^{\text {th }}$ March. In the weekend, the damper was activated in a short period might due to people enter the meeting room. Large deviation up to $2{ }^{\circ} \mathrm{C}$ was found between the temperature measured by Eltek and monitored by BMS sensor. The reason for the large deviation is because the BMS sensor is located next to a big screen, which releases heat and blocks the sensor.

The ventilation system in the auditorium is a VAV system, where the damper can operate from $0 \%$ to $100 \%$. The damper opened 1 hour before the booking time and closed $30 \mathrm{~min}$ after the booking time. However, the damper closed 2 hours before the booking time finished in $15^{\text {th }}$ March and didn't open in $16^{\text {th }}$ March even though the auditorium was booked, which led to the $\mathrm{CO} 2$ reached $3800 \mathrm{ppm}$ in $16^{\text {th }}$ March. In addition, the monitored data indicates that damper either be off or operated around $90 \%$ opening in the observation period. The high damper opening level might due to the high indoor temperature monitored by BMS sensor. The ceiling height of the auditorium is $7.58 \mathrm{~m}$, and the BMS sensor locates on a cabinet at the lower zone. The cabinet is used to store equipment, which has continue heat loads. Therefore, the indoor temperature monitored by the BMS sensor is above the setpoint all the time, which is generally $2{ }^{\circ} \mathrm{C}$ higher than the Eltek sensor located at the same height and $4{ }^{\circ} \mathrm{C}$ higher than the Eltek sensor located in the middle of the auditorium. Another deviation exists at the $\mathrm{CO} 2$ level monitored at the exhaust duct by the BMS sensor and Eltek measured in the lower zone and the middle of the room. The ventilation system in the auditorium is a displacement system, where the exhaust $\mathrm{CO} 2$ is expected to be higher than the one in the occupied zone. However, high CO2 level up to $3800 \mathrm{ppm}$ was measured in the occupied zone in $15^{\text {th }}$ and $16^{\text {th }}$ but the exhaust $\mathrm{CO} 2$ was below $1000 \mathrm{ppm}$. This might be caused by the ventilation system didn't run in $16^{\text {th }}$ March, so the polluted air was not extracted through the exhaust duct.

It is surprised to see that the high $\mathrm{CO} 2$ level was observed in all three rooms in $15^{\text {th }}$ and $16^{\text {th }}$ March. It might due to the high outdoor $\mathrm{CO} 2$ in these two days. However, due to the lack of monitor data on outdoor $\mathrm{CO} 2$ level, we cannot make a solid conclusion.

Figure 4 summarizes the monthly $\mathrm{CO} 2$ concentration in the breathing zone in three rooms. The box presents $25 \%$ $75 \%$ of all measured values during the working hours. The average $\mathrm{CO} 2$ level in office and meeting room are $620 \mathrm{ppm}$ and $537 \mathrm{ppm}$. In the auditorium, the $\mathrm{CO} 2$ are measured at three locations: lower zone, a middle zone, and an upper zone, where the CO2 level is $608 \mathrm{ppm}, 646$ ppm and $700 \mathrm{ppm}$, respectively. The concentration stratification indicates the displacement effect. It can be noticed that $\mathrm{CO} 2$ level exceeds $1000 \mathrm{ppm}$ in all three rooms, although it exists in a very short period, which accounts for $4.1 \%, 3.6 \%$ and $6.3 \%$ of the total working hours in the office, meeting room and auditorium, respectively.

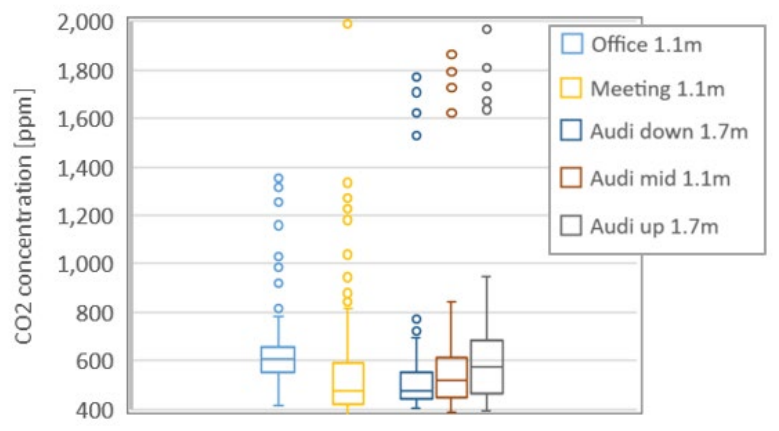

Figure 4: Monthly overview of CO2 level in three rooms in the working hours.

Rotary heat exchangers are used in the ventilation systems to recover heat from the exhaust air. Based on the Danish regulation, heat recovery efficiency should not less than $85 \%$. The heat recovery efficiency could be 
Table 2: Control strategies for different types of room.

\begin{tabular}{l|ccccc}
\hline Room Type & Activation & Damper Opening & $\begin{array}{c}\mathbf{C O 2} \\
{[\mathbf{p p m}]}\end{array}$ & $\begin{array}{c}\text { Setpoint for heating }\left[{ }^{\circ} \mathbf{C}\right] \\
\text { Netpoint for cooling } \\
\left(\text { venting) }\left[{ }^{\mathbf{0}} \mathbf{C}\right]\right.\end{array}$ \\
\hline Offices & PIR & $0 \% / 100 \%$ & NA & 23 & 23 \\
Meeting room & PIR & $0 \% / 40 \% / 100 \%$ & 1000 & 22.5 & 23.5 \\
Auditorium & Booking & $0 \%-100 \%$ & 900 & 24 & 24 \\
\hline
\end{tabular}

\begin{tabular}{l|lll}
\hline Ventilation unit & VE01 & VE02 & VU01-4 \\
\hline Function & Supply\&Exhaust & Supply\&Exhaust & Extraction \\
Target area & Office, meeting room & Auditorium & Toilet \\
Type & Centralized & Centralized & Decentralized \\
Control & VAV & VAV & CAV \\
Max airflow rate $\left[\mathrm{m}^{3} / \mathrm{h}\right]$ & 10800 & 5700 & 468 \\
Heat recovery & Rotary heat exchanger Rotary heat exchanger & Non \\
Distribution principle & Mixing & Displacement & Extraction only \\
\hline
\end{tabular}

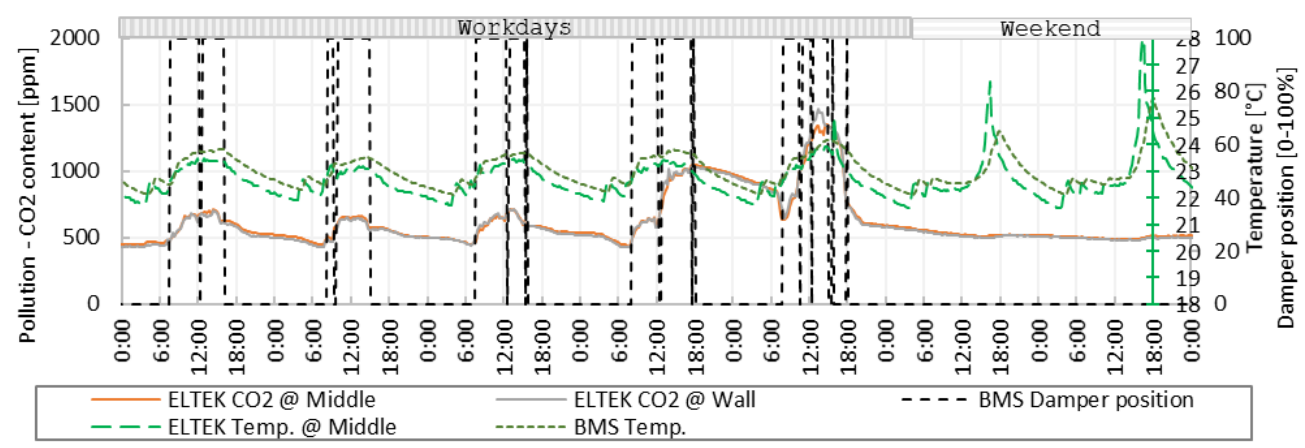

(a)

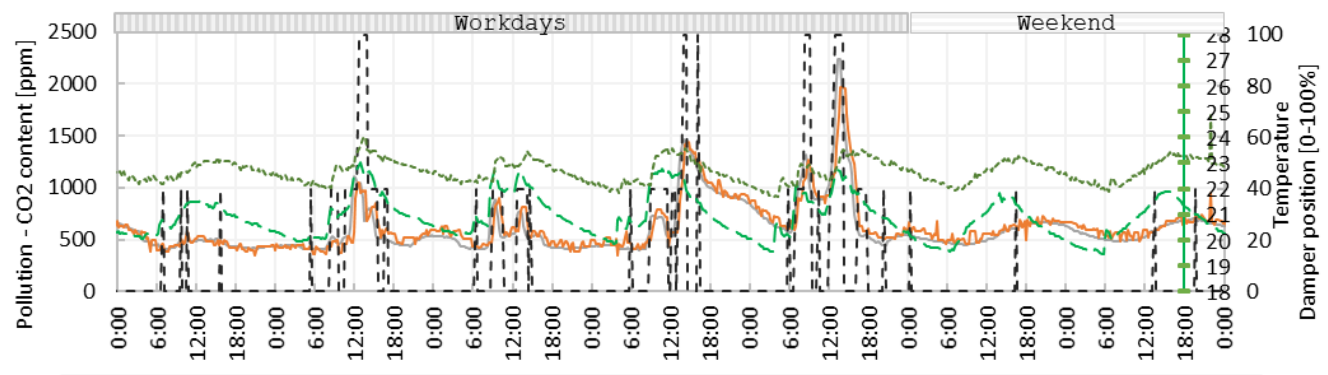

_Eltek CO2 @ sensor _ _ BMS CO2 @ sensor _ - - - BMS Damper position

(b)

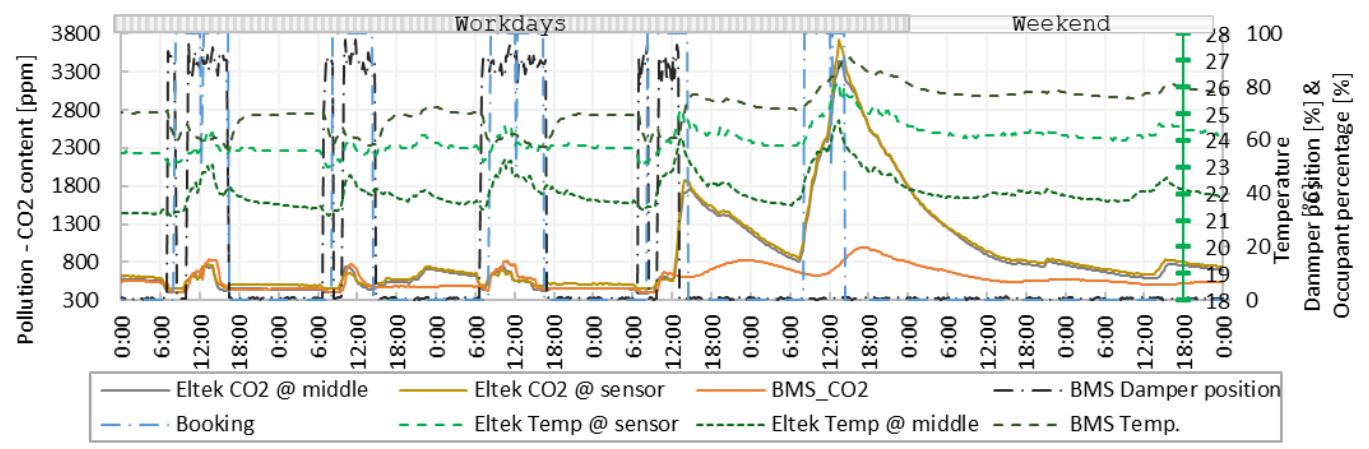

(c)

Figure 5: Operation of ventilation system in three rooms (week 11: 12-18 March 2018) and the comparison of measured and monitored indoor environment. (a) Office; (b) Meeting room; (c) Auditorium 


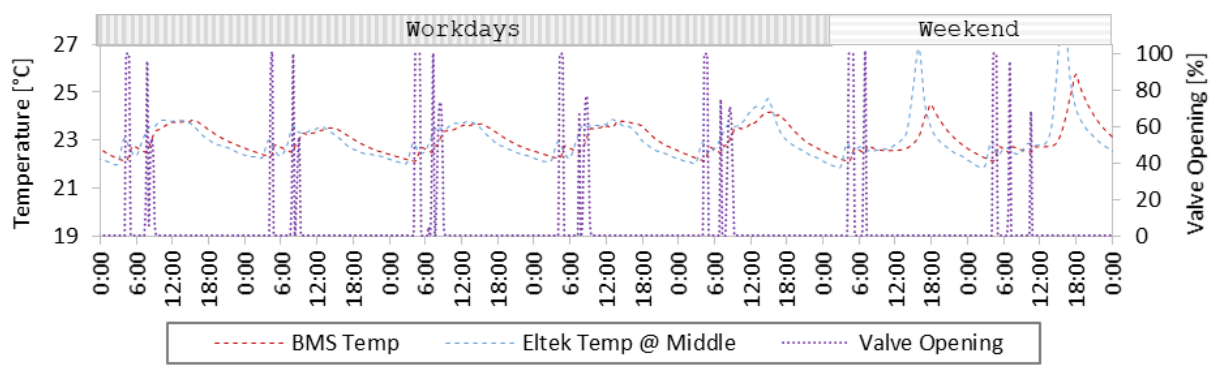

(a)

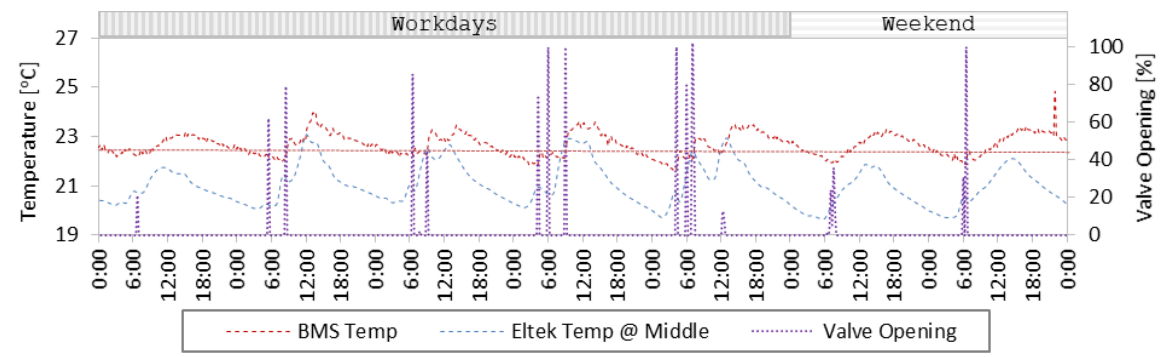

(b)

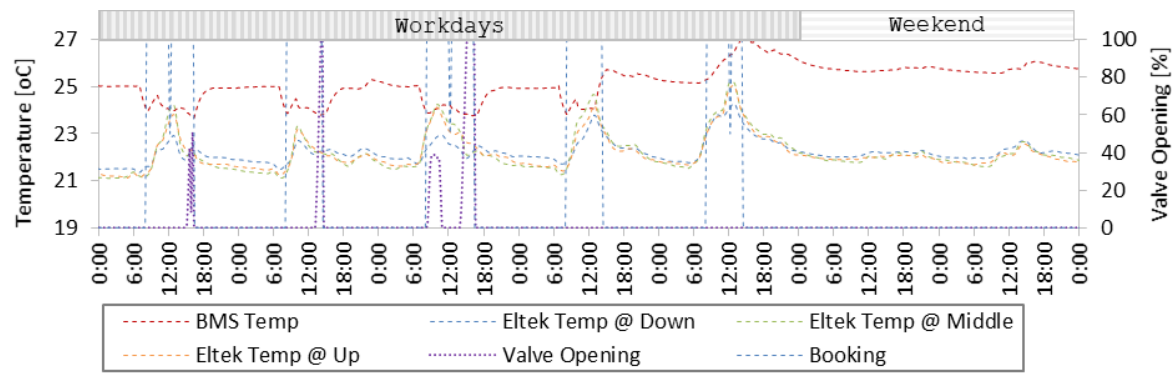

(c)

Figure 6: Operation of the heating system in three rooms (week 11: 12-18 March 2018) and the comparison of measured and monitored temperature. (a) Office; (b) Meeting room; (c) Auditorium

calculated based on the monitored temperatures from the BMS system. The average heat recovery efficiency of VE01 and VE02 are 77\% and 81\%, respectively, which are slightly lower heat recovery efficiency than that required in the BR15.

\section{Heating system}

The operation of the heating system is analyzed in three rooms, as shown in Figure 6. The valve opening of radiators adjusts according to the temperature sensor connected to the BMS system. If the temperature is lower than set-point (shown in Table 2), the valve will be turned on.

In the office, the valve turns on at 4:00 am to preheat the room before occupants show up. It turns on again in the working hours if the temperature from BMS sensor is below the setpoint of $23{ }^{\circ} \mathrm{C}$. The temperature in the occupied zone was measured by Eltek sensor at $1.1 \mathrm{~m}$ height and compared with the values from the BMS sensor. The deviation is less than $0.5^{\circ} \mathrm{C}$ in the weekday but above $3{ }^{\circ} \mathrm{C}$ at the weekend. It is surprising to see that the radiator operates in the same way in the weekend, which results the indoor temperature is even higher in the weekend than the weekdays and it wastes of heating energy.
In the meeting room, the valve turns on between 4:00 am to 6:00 am to preheat the room. The valve turns on again in the working hours if the temperature monitored by the BMS sensor is below the setpoint of $22.5^{\circ} \mathrm{C}$. However, the large deviation is observed between the temperature in the occupied zone measured by ELtek with the BMS sensor located on the wall and the temperature difference is above $2{ }^{\circ} \mathrm{C}$. Therefore, the indoor temperature in the occupied zone ranges from $20^{\circ} \mathrm{C}$ to $23{ }^{\circ} \mathrm{C}$ in the working hours, and from the survey we observe many occupants complained about the low indoor temperature.

In the auditorium, the valve only activates during the booking time and BMS temperature is below the setpoint of $24{ }^{\circ} \mathrm{C}$. However, due to the wrong location of BMS sensor as described in the section above, the actual indoor temperature in the occupied zone is much lower, especially in the first several hours the temperature is even below $21^{\circ} \mathrm{C}$.

The energy efficiency of the heating system is analyzed by observing the supply and return water temperature in the mixing loops. The monitored data from BMS shows the supply temperature between $60-70{ }^{\circ} \mathrm{C}$ in RA01 most of the time, accounting to $71 \%$ of the measuring period. While, the supply temperature is relatively higher in RA02 loops, $64 \%$ of the time between $65-75^{\circ} \mathrm{C}$. 
As stated in the design of the control strategy, the return temperature should be kept below $50{ }^{\circ} \mathrm{C}$. However, RA01 has return temperature above $50{ }^{\circ} \mathrm{C} 33 \%$ of the measured period, while RA02 has $9 \%$. The high return temperature might due to inefficient valve control in the radiator, where the flow rate is too high and the hot water returns back to the loop before releasing sufficient heat. Both of the mixing loops connect to the district heating system and return the water to the grid. In Denmark, the district heating dimensioning temperature is $40^{\circ} \mathrm{C}$ for return. The monitored data from BMS shows that studied building had return temperature above $40{ }^{\circ} \mathrm{C} 77 \%$ of the measured period. It is important to control the return temperature in order to use the heat properly before sending it back to the grid as high return temperatures have an economic consequence.

\section{Energy performance}

Figure 7 shows the building energy consumption from Jan to Nov 2018 in term of electricity and heating. The main consumers of electricity in the building include ventilation systems, lighting, appliances and auxiliary equipment. There is no detail data available on the lighting and applications consumptions, therefore, we divide it into ventilation systems and the others. There is no large variation in electricity consumption during the whole year, where the average monthly consumption is 17 MWh. However, a clear seasonal variation on the electricity consumed by ventilation systems can be seen in Figure 7 (a). It accounts for up to $23 \%$ of total electricity consumption during the summer season and reduces to $6 \%$ in the winter season. The high electricity usage in summer is because ventilation is used to prevent overheating and the ventilation flow rate is much higher than the one used for maintaining the $\mathrm{CO} 2$ level. On the other hand, the lower artificial lighting usage in summer results in no large difference in the overall electricity consumption during the year. The heating consumption is shown in Figure 7 (b), which cover space heating, domestic hot water and heat coil in the ventilation systems. Heating demand has a remarkable seasonal variation, which is about $2.5 \mathrm{MWh}$ in June and $43.8 \mathrm{MWh}$ in February. Due to the lack of data in Dec, the total heating demand in 2018 until Nov is 203.4 MWh and the value for electricity is $203.8 \mathrm{MWh}$.

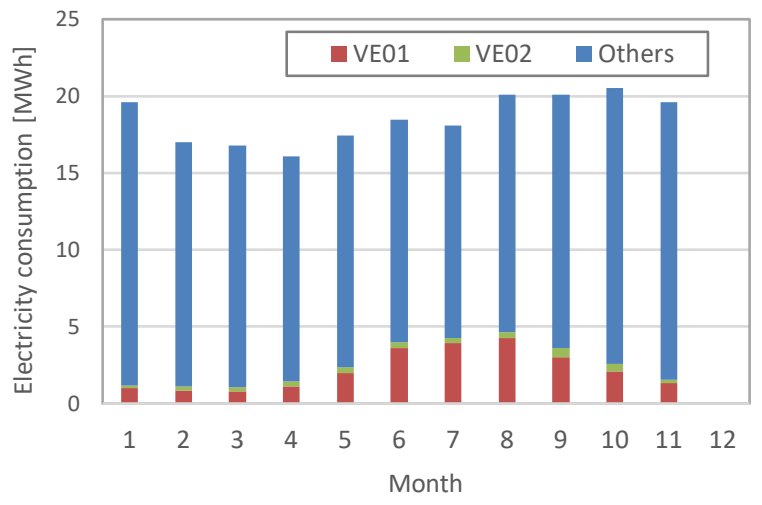

(a)

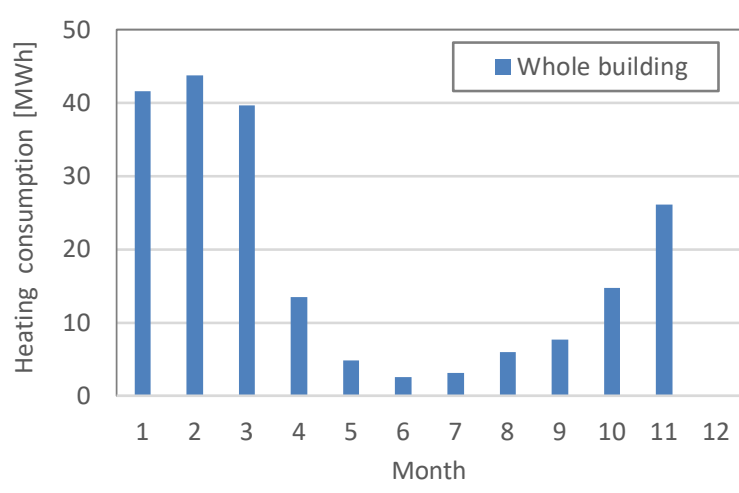

(b)

Figure 7: Building energy consumption 2018 (Data in December is not available). (a) Electricity (b) Heating

\section{Simulation and Optimization}

A dynamic model is developed in BSim to analyze the building performance in term of indoor environment and energy use, and further use to investigate the impact of several optimization strategies on the overall energy performance. Three rooms (office, meeting room and auditorium) are chosen for the simulation to represent the whole building, as shown in Figure 8. The weather file is developed based on the data logged by the weather station near the case building. Each room is represented by a thermal zone which is able to have individual input on the people and equipment load, time schedule and controls for HAVC system. The input values are defined according to the measured data or the monitored data from BMS in order to represent the building system and operation characteristics to a large extent. However, there several uncertain parameters might lead to the deviation between model and real building performance. For example, the real occupant number and occupied hour might differ from the design values; lack of information on lighting and appliance usage; the model assumes a good mixing in the room lead to a uniform temperature and $\mathrm{CO} 2$ level in all positions, etc. To calibrate the model, an iterative process takes place, as explained in Figure 9.

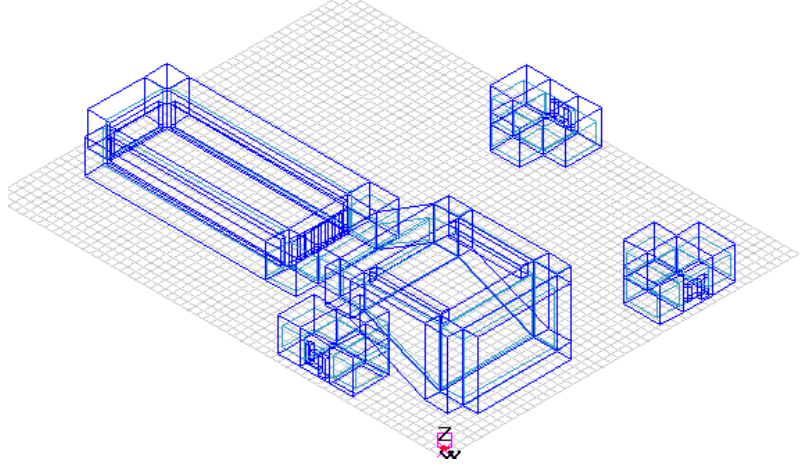

Figure 8: BSim model for case building.

In order to validate the model, the correlation between the on-site measured and simulated temperature and $\mathrm{CO} 2$ level are investigated in three rooms. As an example, Figure 10 shows the results in the auditorium in week 10. It is clear to see a good agreement has been reached between the measured and simulated values. The temperature deviation is less than $1{ }^{\circ} \mathrm{C}$ in the whole week 


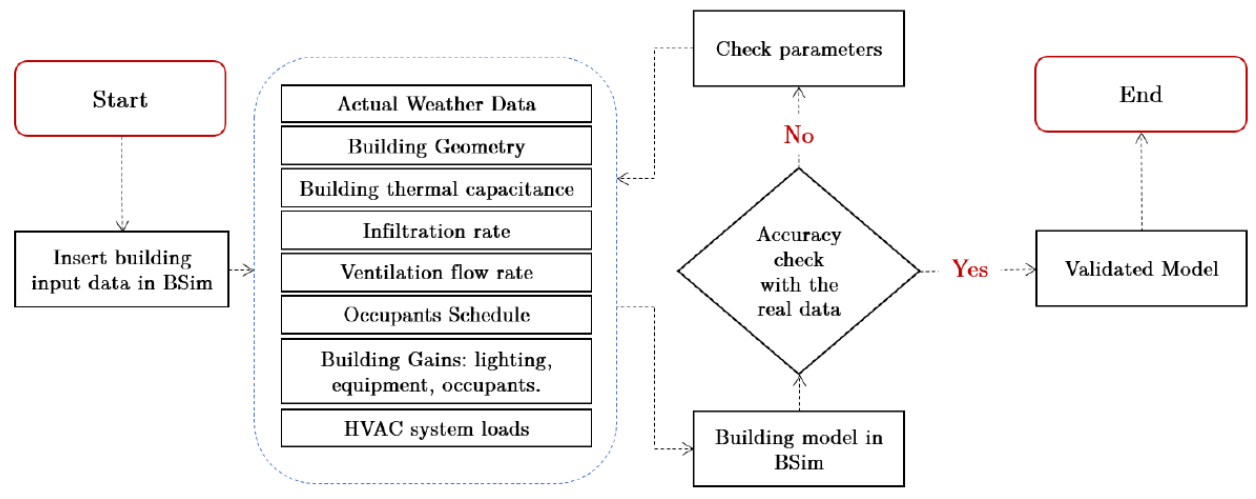

Figure 9: Model calibration process.

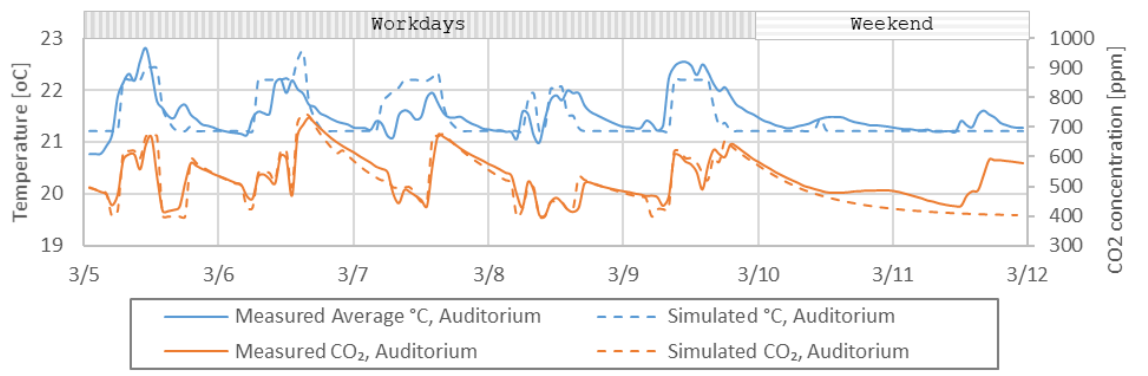

Figure 10: Measured and simulated temperature and CO2 level in the auditorium (Week 10, 5-11 March 2018).

with mean absolute percentage error (MAPE) of $1.12 \%$. The $\mathrm{CO} 2$ values correspond well in the weekday, a large deviation of approximately $200 \mathrm{ppm}$ occurs in the weekend, due to the unexpected occupancy. The MAPE of $\mathrm{CO} 2$ is $5.87 \%$ during the whole validation period. Because the detail energy consumption in the room level is not available, no comparison between the monitored value and simulated value presents here. The accuracy of the model is acceptable and will further use to simulate optimization strategies.

The potential energy saving strategies identified through the commissioning process are summarized below, and their impacts on energy performance are evaluated using the validated model.

1. Adjust heating setpoint: The existing control system indicate that the temperature setpoint for heating and cooling (ventilation) has the same value in office and auditorium, which results in unnecessary energy consumption on heating and ventilation systems to maintain constant indoor temperature. On the other hand, the setpoint temperature for heating is too high and it is suggested to reduce the value to $22{ }^{\circ} \mathrm{C}$ in all the rooms.

2. Adjust heating schedule: As shown in Figure 6, the heating system run with the same setpoint in the weekend in the office and meeting room. It suggests lowering the setpoint in the weekend to $20{ }^{\circ} \mathrm{C}$ (meeting and office).

3. Adjust ventilation setpoint: The function of the ventilation system is both provide acceptable indoor air quality (controlled by $\mathrm{CO} 2$ sensor) and avoid overheating (controlled by a temperature sensor). The setpoint for CO2 is based on EN15251 Category ii that less than $500 \mathrm{ppm}$ above outdoor level. However, the comfort temperature in summer season is $23-26^{\circ} \mathrm{C}$. The setpoint temperature for ventilation (cooling) set up as the lowest valve, which leads to unnecessary energy waste. It suggests increasing the setpoint for ventilation to $25^{\circ} \mathrm{C}$ in the meeting room and auditorium.

4. Increase heat recovery efficiency: The monitor data shows the heat exchangers do not achieve the optimal efficiency as required in the BR15. It is interesting to find out how much energy could be saved by increasing the heat recovery efficiency to even $85 \%$ (class 2020).

Figure 11 summarizes the energy saving potentials by implementing different optimization strategies. It needs to notice only heating demand (space heating and heating coil) and fan power are analyzed here, due to the limitation of the numerical model and lack of detail information on the electricity consumption on other components. As expected, strategy 1 and strategy 2 have a significant impact on the space heating demand in all three rooms, especially in the office the space heating demand decrease from $62 \mathrm{kWh} / \mathrm{m}^{2}$.yr to $34 \mathrm{kWh} / \mathrm{m}^{2}$.yr, which reduce $45 \%$ heating demand. Strategy 3 has a marginal impact on the energy consumption of the fan. It reduces from $19 \mathrm{kWh} / \mathrm{m}^{2}$.yr to $14 \mathrm{kWh} / \mathrm{m}^{2}$.yr in the meeting room and from $46 \mathrm{kWh} / \mathrm{m}^{2}$.yr to $44 \mathrm{kWh} / \mathrm{m}^{2}$.yr in the auditorium. The small impact is because no significant overheating exist in both rooms during summer. The last optimization strategy increases the heat recovery efficiency in the ventilation system and effectively reduce the heating need in the heating coil, therefore, the heating demand further decrease in three rooms. By implementing all the optimization strategies, 
the energy saving potential in the office, meeting room and auditorium are $44 \%, 39 \%$, and $20 \%$, respectively. The indoor environment in term of operative temperature and $\mathrm{CO} 2$ level are checked in each scenario and it is validated that energy saving strategies do not sacrifice the indoor environment.

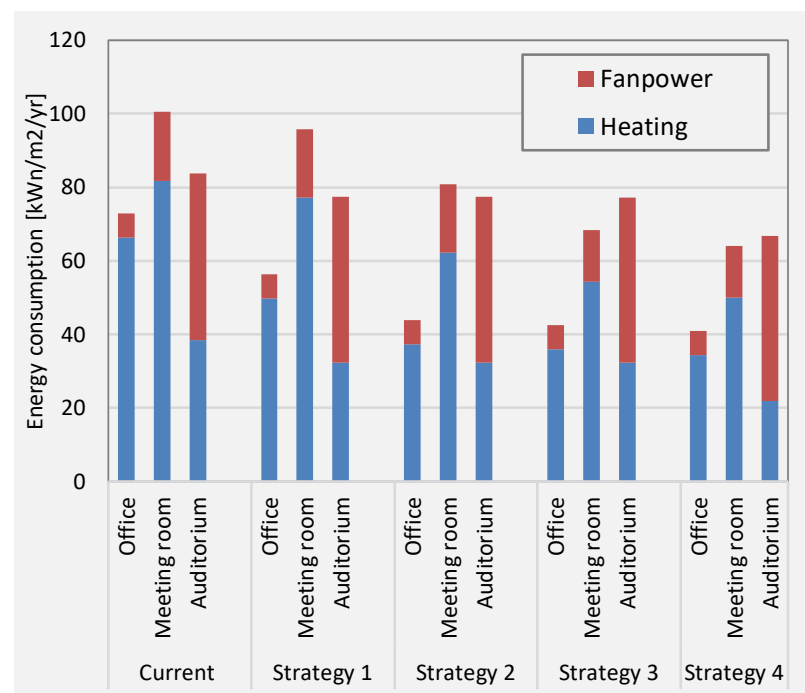

Figure 11: Energy consumption on heating and fan power in three rooms in current condition and optimization strategies.

\section{Conclusions}

This paper demonstrates a case study of commissioning in a campus building. The main focus is to investigate the energy performance of ventilation and heating systems and the indoor environment in three representative rooms: office, meeting room and auditorium. A master list of findings is summarized based on the monitoring data analysis and on-site measurements:

- The temperature and $\mathrm{CO} 2$ sensor in the auditorium and meeting room cannot represent the real condition in the space and lead to inaccurate operation of ventilation and heating system.

- Heat recovery efficiency of VE01 is $77 \%$ and slightly lower than the required value in Building Regulation

- The setpoints temperature for heating and ventilation are the same in the office and auditorium, which result to maintain constant indoor temperature. It is recommended to reduce the setpoint temperature for heating and increase the setpoint temperature for ventilation.

- The return water temperature is too high for the heating systems compared with the value required by the technical document and the recommended value for district heating. It suggests having more precise valve control on the radiator in order to reseal the heat properly before sending it back to the grid as high return temperatures have an economic consequence.

Five optimization strategies have been proposed and their impacts have been evaluated by a validated dynamic model. By implementing all the optimization strategies, the energy saving potential in the office, meeting room and auditorium are $44 \%, 39 \%$ and $20 \%$, respectively.

\section{Reference}

Brown, K., Anderson, M. and Harris, J. (2006). How Monitoring-Based Commissioning Contributes to Energy Efficiency for Commercial Buildings. ACEEE Summer Study on Energy Efficiency in Buildings (Ucop 2004): 27-40.

Dorgan, C. E. et al. (2007). ASHRAE GUIDELINE HVAC \& R Technical Requirements for The Commissioning Process. Building 2007.

Friedman, H. et al. (2010). Annex 47 Report 3: Commissioning Cost-Benefit and Persistence of Savings. National Institute of Standards and Technology, Technical Note 1727.

Harmer, L. C. and Henze, G. (2015). Using Calibrated Energy Models for Building Commissioning and Load Prediction. Energy and Buildings 92: 204-15.

Milesi, N, Miyata, M. and Baumann, O. (2018). A Retrospective on the Impact of Annex 40 and Annex 47 Research on the International State of Building Commissioning. Energy and Buildings 158: 54-61.

Pérez-Lombard, L., Ortiz, J. and Pout, C. (2008). A Review on Buildings Energy Consumption Information. Energy and Buildings 40(3): 394-98.

The Danish Ministry of Economic and Business Affairs. (2015). Danish Building Regulations 2015 (BR15).

Wang, L. et al. (2013). Monitoring-Based HVAC Commissioning of an Existing Office Building for Energy Efficiency. Applied Energy 102: 1382-90. 